\title{
Research on the Influence of Science and Technology Competition on the Cultivation of Innovation Ability of Engineering College Students
}

\author{
Hongbo Shi ${ }^{1}$, Dong Yan $^{2}$ and Xinsheng Wang ${ }^{3, *}$ \\ ${ }^{1,2}$ School of Economics and Management, Harbin Institute of Technology, Weihai, China \\ ${ }^{3}$ School of Information Science and Engineering, Harbin Institute of Technology, Weihai, China \\ *Corresponding author. Email: wangxs@hitwh.edu.cn
}

\begin{abstract}
The extracurricular science and technology (S\&T) competition, as an important means of cultivating students' innovative ability, has a special educational function, and plays an increasingly positive role in cultivating compound and innovative talents and promoting the combination involving production, teaching and research in colleges and universities. This paper selects some engineering college students who have participated in S\&T competitions in Shandong Province as the research object. Through in-depth analysis, this paper studies the influence mechanism of S\&T competitions on college students' innovation ability from three aspects of innovation individual, innovation environment and innovation behavior, and obtains the expected results.
\end{abstract}

Keywords: Engineering college students, S\&T competition, Innovation ability.

\section{INTRODUCTION}

How to cultivate engineering talents has always been a hot topic in the field of higher education. Talent training mainly includes the following aspects: clear training objectives, scientific training mode, potential cultivable talents and excellent and responsible trainers [1]. The campus is the initial soil of talent cultivation, and the cultivation of innovative engineering talents must start from college students.

\subsection{Research Background and Significance}

At the beginning of the reform and opening up, some extracurricular competition activities with the theme of S\&T, mainly participated by college students, began to appear in the field of higher education in China. This kind of competition has various functions and wide themes. Some of the events are closely related to professional education in colleges and universities, and complement classroom teaching; some competitions emphasize the review of the participants' exploration and innovation ability. These competitions cover 11 disciplines or fields such as mathematics, physics and chemistry, with an annual number of more than one million participants. In just a few decades, they have rapidly developed into a kind of extracurricular activities that cannot be ignored [2].

The purpose of this paper is to explore the influence mechanism of S\&T competition on the innovation ability of engineering college students, analyze the connotation and connection between S\&T competition and innovation ability, explore the influence factors of innovation ability, and then put forward the opinions on the cultivation mechanism of innovative engineering talents from the three levels of students, colleges and the state.

S\&T competition is a competitive combat in the special field to compare the level of scientific research ability, which is carried out outside the classroom and has a close relationship with the curriculum, and needs to use multidisciplinary knowledge to solve social problems or academic questions. Such competition activities undoubtedly supplement the deficiency of classroom teaching. Therefore, this study can provide a certain reference for how to improve the innovation ability of college students. 


\subsection{Research Status and Comments at Home and Abroad}

This research is mainly divided into two aspects: one is the in-depth study of S\&T competition itself; on the other hand, it studies the impact of S\&T competition.

At the end of the 20th century, American scholars Laune Somers and Susan Callen carried out a series of researches on 60 science and mathematics competitions through the Internet and other information channels, and carefully examined 36 competitions. The study classifies these S\&T competitions from 12 aspects, and sums up six categories [3].

At the beginning of the 21st century, Kennedy investigated the European Union Science Olympiad and found that it had three objectives. First, challenge potential innovative talents with the help of S\&T competition to stimulate their thirst for knowledge in scientific research direction; second, promote the development of science and make it a career; third, to encourage the exchange of teachers and students among European countries, and to improve and promote the scientific level of EU Member States.

In 2004, The Science Olympiad Foundation conducted a long-term follow-up survey of hundreds of outstanding contestants. The results showed that almost all the participants who responded believed that participating in S\&T competitions fostered their interest in science and increased their thirst for knowledge in exploring scientific knowledge.

Up to now, in China S\&T competitions have been held for a relatively short time, and the forms and characteristics of the activities are also relatively few. The research in this area focuses on the discussion of the theoretical direction of S\&T competitions, while the discussion on its application is less.

Du Huiping studied and investigated the activity system of S\&T competition, and pointed out that talent training should include three aspects: the management system of S\&T competition, the construction of participating teams, and the mechanism of student selection and training [4]. By analyzing the necessity of undergraduate S\&T competition, S\&T competition activities can be explored. Based on previous research, we hold a view that innovation ability is mainly composed of innovative thinking ability, nonintellectual factors and innovative practice ability.

In China, the academic research on Chinese college students' S\&T competition is still relatively weak compared with foreign countries. On the one hand, there is a lack of literature from a more macro perspective; on the other hand, there is a lack of specialized analysis of various details by using a variety of methods.
S\&T competitions in Europe and the United States have been carried out for a long time and have a relatively large impact. They have been recognized and widely supported by the education sector, the scientific community, enterprises and the government. In addition, the operation mode of S\&T competitions in European and American countries has been socialized and commercialized, and there is a good societal participation mechanism, so the research on it is emerging in endlessly and gradually mature.

Generally speaking, the current research on extracurricular S\&T competition activities in the cultivation of university talents' innovation ability is attracting attention, and some research results have been obtained. However, based on the current situation of college students' S\&T competitions at home and abroad, there is little research on the logical relationship between the cultivation of non-professional ability and the improvement of the innovation ability of the participants.

In the college stage, the study of theoretical and professional knowledge in the course often needs to be more interesting and effective in practical activities. And participating in the corresponding professional S\&T competition is one of the specific manifestations of this practice process. According to the results of the previous questionnaire survey, generally speaking, college students hold a positive attitude to participate in S\&T competitions currently.

\section{THEORETICAL ANALYSIS ON THE INFLUENCING FACTORS OF S\&T COMPETITION}

\subsection{The Present Situation of S\&T Competition Participation}

S\&T competition is one of the effective ways to cultivate innovative talents with high scientific research quality. It plays an important role in cultivating students' innovative spirit, improving practical ability and strengthening the ability of integrating theory with practice. In addition, S\&T competition is also an important way to show students' all aspects of literacy, school teaching level and teaching reform results [5].

At present, S\&T competition has become an indispensable part of college students in the semesters. Therefore, the S\&T competition in colleges and universities have received certain attention.

\subsection{The Influence of $S \& T$ Competition on Innovation Ability}

The impact of S\&T competition on competitors can be roughly interpreted from three aspects: first, the impact of S\&T competition on innovation ability 
through innovation individuals; second, the impact of S\&T competition on innovation ability through innovation environment; third, the impact of S\&T competition on innovation ability through innovation behavior. The following is a detailed analysis of the relationship between innovation ability and competition activities [6].

\subsubsection{The Relationship between Innovation Individual and Innovation Ability}

Jalil and Boujettif studied the Nobel Laureates using the traditional research methods of creative personality, and found five characteristics of creative personality: developmental \& systematic, interactive, pluralistic, constructive and experienced. Therefore, through previous studies, we found that innovation ability and individual characteristics are interrelated. The influence of innovative individuals is the characteristics and motivation of individuals participating in innovative behavior in the process of competition. Therefore, it should be specifically divided into the influence of innovative characteristics and innovative motivation. Students' own qualities related to innovative traits have a great influence on their creativity, such as students' innovative attitude, innovative personality, and innovative motivation and so on [7].

Innovation trait refers to the individual will and thinking participating in innovation behavior, which can be roughly summarized as innovative thinking and innovative will. Innovative thinking is not only the precondition of creative practice, but also the cornerstone of innovative ability. Meanwhile, similar to personal way of thinking, confidence and tenacity are the characteristics that affect the ability of innovation. In addition, the innovation cycle of participating in S\&T competition is long, so the motivation of the participants should be constantly stimulated and encouraged.

In terms of motivation, Amabile pointed out that motivation plays a mediating role between innovation and environment. Choi further found that external motivation can improve innovation performance through innovation intention.

Innovation motivation can be divided into intrinsic motivation and extrinsic motivation, and extrinsic motivation is reward motivation [8]. Through the data of questionnaire survey, we can know that resume and bonus are one of the motivations of all participants. After taking part in a competition, accumulating for future choice, the improvement of self-ability and understanding of like-minded friends began to become the main driving force. Among them, accumulation for the future has become the highest driving force.

Here, adding points to your resume and accumulating for your future choices belong to the external reward motivation, while the improvement of your ability and the recognition of like-minded friends belong to the internal motivation.

\subsubsection{The Relationship between Innovation Environment and Innovation Ability}

Innovation environment should include system environment and management environment. The institutional environment refers to the incentive and support for innovative behavior (participation) by the organizers and schools of S\&T competitions, and the management environment refers to the internal atmosphere management and competition process management of the team formed by the participants [9].

As far as the institutional environment is concerned, first of all, S\&T competitions have their own rules, and schools also have certain supporting policies for participating in S\&T competitions. Studies have shown that school atmosphere and class atmosphere will have mutual influence on teachers. It can be seen that school environment not only affects students' creativity, but also affects teachers' individual characteristics and teaching behavior.

Management environment mainly includes school interpersonal experience and family relations, such as teachers, peers, parents, etc., especially teachers' classroom teaching and family education. Moreover, this kind of environment can act on individual characteristics and influence the development of innovation ability through individual innovation. Especially the interpersonal relationship between teachers and students is very important, just as some scholars found that mutual respect between teachers and students, open dialog and cooperation can promote the development of students' innovation ability. It can be seen that teachers affect the development and cultivation of students' innovative ability.

\subsubsection{The Relationship between Innovation Behavior and Innovation Ability}

Innovative behavior should include the knowledge structure and practical ability of college students.

The knowledge structure that affects college students' innovation ability can be summarized as the following two kinds: professional knowledge, manuscript writing and presentation. In college students' extracurricular S\&T competition activities, it is usually required to write project application, project assignment, project opening report, interim report and achievement summary report. In the writing of relevant documents, it is required to be clear-cut, well structured, fluent in writing, fluent in language, correct in method, sufficient in analysis and demonstration, accurate in design and calculation, and accurate in professional terms, and so forth. This series of processes help to cultivate students' innovative thinking ability, and under the guidance of 
innovative thinking, it is easier to stimulate students' innovative desire.

The practical ability in innovative behavior includes information communication and experimental operation. Information communication is not only the progress communication with instructors and team members, but also the interpersonal communication needed to solve problems in the face of difficulties. Experimental operation is to provide the guarantee of the entries, excellent works cannot be done without good experimental operation, and it is also the experimental operation that can specifically show the creativity in innovative thinking.

\section{INFLUENCE SURVEY AND ANALYSIS OF S\&T COMPETITION}

\subsection{Target Problem Description}

On the basis of the previous research, this paper uses the method of questionnaire survey to empirically analyze the data from the survey and verify the above theory; and then to explore whether it is an effective way to cultivate students' innovation ability to participate in extracurricular S\&T competition in the face of the practical needs of students' innovation ability.

\subsubsection{Purpose of Empirical Investigation}

Through the form of questionnaire to investigate the impact of extracurricular S\&T competition on college students' innovation ability, the study investigates the current situation of extracurricular S\&T competition and participation. Taking the "Challenge Cup" National College Students' S\&T Competition as an example, this paper analyzes the correlation between it and college students' innovation ability from various aspects. To understand the current situation of college students' participation in extracurricular S\&T competitions and the impact of these activities on their innovation ability, as well as their future choices (further study, employment, entrepreneurship). At the same time, we should understand the important role and effective methods of different subjects in the cultivation of innovation ability.

\subsubsection{Empirical Investigation Method}

According to the previous research and related literature, self-designed questionnaire was prepared. Considering the situation of students' participation in extracurricular S\&T competitions in recent three years, in the selection of survey objects, in order to ensure the strong representativeness of object selection, the distribution objects include college students in Shandong Province. To ensure the authenticity and accuracy of the questionnaire information, in the process of distribution, we strictly insist that one person one copy. In this survey, 200 questionnaires were distributed and 164 were recovered, with a recovery rate of $82 \%$. Among them, 82 were effective questionnaires, with a recovery rate of $100 \%$.

\subsection{Data Analysis}

\subsubsection{Reliability Analysis}

It can be seen from table 1 that the reliability coefficient is 0.893 , which is greater than 0.8 , indicating that the reliability quality of the research data is high. For deleted items $\alpha$, there was no significant improvement in the reliability coefficient after the analysis item was deleted. Therefore, all the items should be retained and the reliability level of the research data is high. For "CITC value", the reliability coefficient of the research data is higher than 0.8 , and the reliability coefficient will not be significantly improved after deleting the item. In conclusion, the reliability of the data is high and can be used for further analysis.

\subsubsection{Descriptive Statistics}

Sample survey grades: Freshmen and sophomores accounted for $2.94 \%$, juniors \& seniors accounted for $73.53 \%$, graduate students accounted for $19.12 \%$, and employed people accounted for $4.41 \%$. From the perspective of data sources, taking junior and senior college students and graduate students as the main body of the survey, it avoids the impact of the shorter of time for college students and the lack of opportunities to participate in S\&T competitions. Among the respondents, $61.76 \%$ did not participate in the S\&T competition, and $38.24 \%$ participated in the competition. It can be seen that a small number of students in the sample have participated in the extracurricular S\&T competition. The competition involves a small area, and students need to be encouraged to participate actively.

After the cross analysis of the number of times and motivation of participating in the competition, we can clearly see that resume and bonus points are one of the motivations of all participants. After taking part in a competition, accumulating for future choices, improving self-ability and building up contacts have become the main driving force. Among them, accumulation for the future has become the highest driving force. 
Table 1. Reliability analysis

\begin{tabular}{|l|l|l|l|}
\hline \multicolumn{1}{|c|}{ Terms } & $\begin{array}{l}\text { Corrected item total } \\
\text { correlation (CITC) }\end{array}$ & $\begin{array}{l}\text { Item deleted } \alpha \\
\text { coefficient }\end{array}$ & $\begin{array}{l}\text { Cronbach } \alpha \\
\text { coefficient }\end{array}$ \\
\hline Thinking characteristics & -0.11 & 0.871 & 0.8903 \\
\hline Characteristics of consciousness & 0.027 & 0.867 & \\
\hline Innovation motivation & 0.221 & 0.863 & \\
\hline Innovation ability & 0.918 & 0.827 & \\
\hline Knowledge structure & 0.968 & 0.821 & \\
\hline Practical ability & 0.973 & 0.825 & \\
\hline Institutional environment & 0.834 & 0.952 & \\
\hline Home environment & 0.785 & 0.953 & \\
\hline Management environment & 0.823 & 0.953 & \\
\hline
\end{tabular}

Table 2. Analysis of competition influence

\begin{tabular}{|l|l|l|c|}
\hline \multicolumn{2}{|c|}{} & Q1 & Q2 \\
\hline \multirow{2}{*}{$\begin{array}{l}\text { What achievements have you made in S\&T } \\
\text { competitions (Q1) }\end{array}$} & Pearson correlation & 1 & .334 \\
\cline { 2 - 4 } & Significant (bilateral) & .000 \\
\cline { 2 - 4 } & $\mathrm{N}$ & 70 & 70 \\
\hline \multirow{2}{*}{$\begin{array}{l}\text { How many times have you been involved in } \\
\text { S\&T competition (Q2) }\end{array}$} & Pearson correlation & .334 & 1 \\
\cline { 2 - 4 } & Significant (bilateral) & .000 & 70 \\
\cline { 2 - 4 } & $\mathrm{N}$ & 70 & 70 \\
\hline
\end{tabular}

Table 3. Number of entries and impact analysis

\begin{tabular}{|l|l|c|c|}
\hline \multicolumn{2}{|l|}{} & Answer to Q1 & Answer to Q2 \\
\hline \multirow{2}{*}{$\begin{array}{l}\text { How many times have you been involved in competition (Q1) } \\
\text { S\&T }\end{array}$} & Pearson correlation & $.964^{* *}$ \\
\cline { 2 - 4 } & Significant (bilateral) & .000 \\
\cline { 2 - 4 } & $\mathrm{N}$ & $.964^{* *}$ & 70 \\
\hline \multirow{2}{*}{$\begin{array}{l}\text { Are there any other achievements due to } \\
\text { the influence of the competition (Q2) }\end{array}$} & Pearson correlation & .000 & 70 \\
\cline { 2 - 4 } & Significant (bilateral) & 70 & 70 \\
\hline \multirow{2}{**}{ There was significant correlation at the level of .01 (unilateral) } & & \\
\hline
\end{tabular}

Table 4. Impact analysis of innovation ability

\begin{tabular}{|l|l|l|l|l|l|l|}
\hline \multicolumn{1}{|c|}{ Topics / Options } & 1 & 2 & 3 & 4 & 5 & Average \\
\hline Innovative thinking & $2(7.69 \%)$ & $1(3.85 \%)$ & $12(46.15 \%)$ & $4(15.38 \%)$ & $7(26.92 \%)$ & 3.5 \\
\hline Innovative literacy & $2(7.69 \%)$ & $0(0 \%)$ & $14(53.85 \%)$ & $3(11.54 \%)$ & $7(26.92 \%)$ & 3.5 \\
\hline Innovative consciousness & $1(3.85 \%)$ & $1(3.85 \%)$ & $12(46.15 \%)$ & $5(19.23 \%)$ & $7(26.92 \%)$ & 3.62 \\
\hline Subtotal & $5(6.41 \%)$ & $2(2.56 \%)$ & $38(48.72 \%)$ & $12(15.38 \%)$ & $21(26.92 \%)$ & 3.54 \\
\hline
\end{tabular}

\subsubsection{Influence Analysis of Competition Results}

As shown in Table 2, from the perspective of correlation test, the correlation factor $r=0.334$, indicating that the number of times to participate in the competition has a significant impact on whether or not to achieve results. It shows that in the process of college students' participating in S\&T competition, their innovative thinking has been developed, their innovative quality has been improved, and their comprehensive innovative ability has been honed. 


\subsubsection{The Influence of Innovation Ability Training before Competition on Competition Results}

The results show that from the data point of view, $64.29 \%$ of the students have made achievements after taking innovative education courses, 57.14\% after participating in innovative activities, 50\% after participating in scientific research projects, and $46.67 \%$ after participating in social research. However, those who have never participated in innovative practice activities before the competition fail to achieve results.

\subsubsection{Are There Any Other Achievements}

Data show that the proportion of other achievements due to competition is about $42.31 \%$.

As shown in Table 3, in the correlation test between the number of competitions and other influences after competition, the correlation factor $r=0.964$, indicating that this factor is positively correlated with students' innovation ability. With the increase of factor value, the factors of students' other achievements are also increasing, which shows that S\&T competition has a significant impact on students' innovation ability. After the training of competition, the innovation ability of college students becomes stronger.

\subsubsection{Analysis on the Influence of Innovation Ability}

As shown in Table 4, in the influence analysis of innovation ability, the average score of the matrix is 3.54. And the influence score of innovative consciousness is higher than the average score, which indicates that college students think that innovative consciousness is the most important influencing factor of innovation ability. The scores of innovative thinking and innovative literacy are consistent, which shows that the weight of the two is consistent in most people's minds. Innovative thinking, innovative literacy and innovative consciousness have little difference, which also shows that most people think that the three complement each other and are indispensable.

\section{CONCLUSION}

At present, the engineering college students' attention to extracurricular S\&T competition is not enough, their understanding is limited, and their participation rate is low. Among the motivations of participating in the competition, resume bonus is a necessary choice for most people, and it also has a certain impact on the results of the competition. That is, the motivation of participating in the competition has an impact on the formation of students' innovation ability. From the above research, we can see that the number of times to participate in S\&T competitions is significantly related to the results and the influence after the competition, and the students who have participated in S\&T competitions have more advantages in the later innovation activities.

Another point is worth emphasizing. From the survey, we can see that students realize that the trinity of consciousness, literacy and thinking is indispensable for innovation ability. However, in their practical actions, they inevitably tend to neglect the importance of innovation consciousness.

\section{AUTHORS' CONTRIBUTIONS}

Writing: Hong-bo SHI, Dong YAN. Providing revising advice: Xin-sheng WANG.

\section{ACKNOWLEDGMENTS}

Sponsored by Ministry of Education humanities and social sciences research project special task (18JDGC014), Shandong colleges' research project of teaching reform (M2018B336), and the fundamental research funds for the central universities (HIT.HSS.HXJS202006).

\section{REFERENCES}

[1] Sui Yifan. University: How to cultivate innovative talents-also on the successful experience of famous American universities [J]. China Higher Education Research, 2006, (12): 3-9.

[2] Zhu Zongning, Mei Deqing, et al. Significance and measures of college students' scientific research activities on the cultivation of innovative talents [J]. Youth, 2018, (34): 144-146.

[3] Guo Yuhong, Xue Haiping, Wang Fei. Review of foreign youth S\&T competitions [J]. Shanghai Education \& Scientific Research, 2010, (9): 32-36.

[4] Du Huiping. Cultivation of innovative talents based on competitions and scientific \& technological activities [J]. China Science and Education Innovation Guide, 2009, (8): 31-32.

[5] B. Z. Mirdjonovna, P. Z. Abdumalikovna, et al. Integration of education, science and production: Social-philosophical aspects [J]. European Journal of Research and Reflection in Educational Sciences, 2020, 8(12): 48-50.

[6] Jin Lingzhi, He Wei. Recognition of innovation performance influencing factors of doctoral students in science and engineering $[\mathrm{J}]$. Research on Higher Engineering Education, 2011, (3): 133139.

[7] Zhang Xiaomeng, Bartol K. M. The influence of psychological empowerment, intrinsic motivation, 
and creative process engagement $[\mathrm{J}]$. Academy of Management Journal, 2010, 53(1): 107-128.

[8] Xue Gui, Dong Qi, et al. Study on the relationship between internal motivation, external motivation and creativity $[\mathrm{J}]$. Psychological Development and Education, 2001, (1): 6-11.
[9] Xiang Yangxue, Chen Jin. Research on new ecommerce talents training mode based on technology and business driven $[\mathrm{J}]$. Research on Higher Engineering Education, 2020, (6): 73-80. 